\title{
Anti-Endoglin Immunotoxin
}

National Cancer Institute

\section{Source}

National Cancer Institute. Anti-Endoglin Immunotoxin. NCI Thesaurus. Code C2003.

Monoclonal antibody K4-2C10 conjug ated with deglycosylated ricin A chain. This antibody recognizes human endog lin (Transforming Growth Factor P Receptor III), present on tumor vasculature. 